\title{
ROLE OF HYPOXIA AND GROWTH AND DIFFERENTIATION FACTOR-5 ON DIFFERENTIATION OF HUMAN MESENCHYMAL STEM CELLS TOWARDS INTERVERTEBRAL NUCLEUS PULPOSUS-LIKE CELLS
}

\author{
J.V. Stoyanov ${ }^{1}$, B. Gantenbein-Ritter ${ }^{2}$, A. Bertolo ${ }^{1}$, N. Aebli ${ }^{3}$, M. Baur ${ }^{4}$, M. Alini ${ }^{5}$ and S. Grad ${ }^{5 *}$ \\ ${ }^{1}$ Spinal Injury Research, Swiss Paraplegic Research, Nottwil, Switzerland \\ ${ }^{2}$ ARTORG Center for Biomedical Engineering Research, University of Bern, Bern, Switzerland \\ ${ }^{3}$ Swiss Paraplegic Center, Nottwil, Switzerland \\ ${ }^{4}$ Cantonal Hospital of Luzern, Luzern, Switzerland \\ ${ }^{5} \mathrm{AO}$ Research Institute Davos, Switzerland
}

\begin{abstract}
There is evidence that mesenchymal stem cells (MSCs) can differentiate towards an intervertebral disc (IVD)like phenotype. We compared the standard chondrogenic protocol using transforming growth factor beta-1 (TGFß) to the effects of hypoxia, growth and differentiation factor-5 (GDF5), and coculture with bovine nucleus pulposus cells (bNPC). The efficacy of molecules recently discovered as possible nucleus pulposus (NP) markers to differentiate between chondrogenic and IVD-like differentiation was evaluated. MSCs were isolated from human bone marrow and encapsulated in alginate beads. Beads were cultured in DMEM (control) supplemented with TGFß or GDF5 or under indirect coculture with bNPC. All groups were incubated at low $(2 \%)$ or normal $(20 \%)$ oxygen tension for 28 days. Hypoxia increased aggrecan and collagen II gene expression in all groups. The hypoxic GDF5 and TGF $\beta$ groups demonstrated most increased aggrecan and collagen II mRNA levels and glycosaminoglycan accumulation. Collagen I and X were most up-regulated in the TGFß groups. From the NP markers, cytokeratin-19 was expressed to highest extent in the hypoxic GDF5 groups; lowest expression was observed in the TGF $\beta$ group. Levels of forkhead box F1 were down-regulated by TGF $\beta$ and up-regulated by coculture with bNPC. Carbonic anhydrase 12 was also down-regulated in the TGF 3 group and showed highest expression in the GDF5 group cocultured with bNPC under hypoxia. Trends in gene expression regulation were confirmed on the protein level using immunohistochemistry. We conclude that hypoxia and GDF5 may be suitable for directing MSCs towards the IVD-like phenotype.
\end{abstract}

Keywords: Stem cells, chondrogenesis, tissue engineering, intervertebral disc, nucleus pulposus, growth factors, hypoxia, growth differentiation factor-5.

*Address for correspondence:

Sibylle Grad

AO Research Institute Davos

Clavadelerstrasse 8

CH-7270 Davos, Switzerland

Telephone Number: +41 814142480

FAX Number: +41 814142288

E-mail: sibylle.grad@aofoundation.org
Introduction

The intervertebral disc (IVD) functions to absorb loads on the spinal column and to provide the flexibility required to allow flexion and extension of the spine. IVD degeneration is associated with a degradation of extracellular matrix molecules, leading to a dehydration of the highly hydrated central nucleus pulposus (NP). The mechanical instability resulting from structural failure is believed to cause pain and disability in a large number of patients (Adams and Roughley, 2006). Biological approaches including cell therapy and tissue engineering have been investigated as promising treatment strategies (Grad et al., 2010). Among those, mesenchymal stem cells (MSCs) hold great potential for regenerative therapy, since they have the ability to differentiate into various cell types of the mesenchymal lineage (Pittenger et al., 1999; Chamberlain et al., 2007) and can be harvested and cultured relatively easily. Therapeutic application of MSCs for bone and cartilage repair and regeneration has widely been investigated (Salgado et al., 2006), and recent studies have demonstrated the feasibility of MSC injection to reverse or retard degenerative disorders of the IVD (Sakai et al., 2008; Ganey et al., 2009; Richardson et al., 2010). In fact there is growing evidence from both in vitro and in vivo studies that MSCs can differentiate into NP-like cells of the IVD (Le Maitre et al., 2009; Yang et al., 2009). However, while standard procedures have been established for in vitro differentiation of MSCs into osteoblastic or chondrocytic cells (Caplan, 1991; Pittenger et al., 1999), no such protocol exists to date for direction of MSCs towards the NP cell phenotype; though a fundamental requirement for tissue engineering or regeneration both in vitro and in vivo is a population of cells capable of forming the appropriate target tissue.

Several approaches have been proposed for in vitro differentiation of MSCs into IVD or NP-like cells (Leung et al., 2006; Paesold et al., 2007; Sakai, 2008). Given that the cells that populate the NP have been recognised to closely resemble the cells of cartilaginous tissues, identical or similar culture conditions have been applied for chondrogenic and disc-like differentiation of MSCs. These include culture in a three-dimensional environment, growth and differentiation factor supplementation, low oxygen tension, hydrostatic pressure as mechanical stimulus, coculture with IVD cells, or a combination of these mediators. For example, when rat MSCs were cultured in alginate beads under hypoxic conditions and supplementation of transforming growth factor beta 
(TGF $\beta$ ), differentiation towards a phenotype consistent with that of NP cells was observed (Risbud et al., 2004). Besides TGF $\beta$, routinely used as standard chondrogenic factor, growth and differentiation factor 5 (GDF5), also known as cartilage-derived morphogenetic protein-1 (CDMP-1), had previously been shown not only to play a key role in skeletal development (Francis-West et al., 1999) but also to induce chondrogenic differentiation of MSCs (Bai et al., 2004; Feng et al., 2008). Furthermore, coculture with human NP cells was shown to induce differentiation of human bone marrow derived MSCs as assessed by significant increases in chondrogenic gene expression and extracellular matrix production (Richardson et al., 2006; Sobajima et al., 2008).

However, only a direct comparison of the capability of various environmental factors to induce an NPlike phenotype in MSCs can evaluate distinctions in differentiation potential. In the present study we measured the influence of hypoxia on human bone marrow derived MSCs in three dimensional alginate cultures as a modulator of the effects of transforming growth factor beta 1 (TGF $\beta 1$ ), GDF5 and coculture with bovine nucleus pulposus cells (bNPC), for the purpose of inducing an IVD-like phenotype. Hypoxic conditions applying $2 \%$ oxygen tension were chosen to mimic the avascular hypoxic environment of the NP tissue; previous studies had shown enhanced chondrogenic and NP-like differentiation in MSCs cultured under 2-3\% oxygen (Risbud et al., 2004; Felka et al., 2009; Baumgartner et al., 2010; Markway et al., 2010). We hypothesised that different combinations of hypoxia with growth factors or coculture may have synergistic or modulatory effects and some of these combinations may result in a differentiation pattern approaching that of IVD cells. In order to potentially distinguish between chondrogenic and IVD-like differentiation, we not only monitored the expression of characteristic chondrogenic genes and glycosaminoglycan (GAG) accumulation, but also the expression of genes that had been found up-regulated in NP compared to annulus fibrosus cells or articular chondrocytes, namely cytokeratin 19 (KRT19) (Lee et al., 2007; Rutges et al., 2010), forkhead box F1 (FOXF1), and carbonic anhydrase 12 (CA12) (Minogue et al., 2010). The intermediate filament protein KRT19, the transcription factor FOXF1, and the carbonic anhydrase CA12 have been suggested as potential NP markers, although their roles in IVD structure and function have barely been investigated yet. These molecules were, however, identified based on large scale gene expression profiling of NP cells in comparison to chondrocytes (Lee et al., 2007; Minogue et al., 2010; Rutges et al., 2010).

\section{Materials and Methods}

\section{Isolation of MSCs from human bone marrow}

Informed consent was obtained from each donor and approval was given by the ethics committee of canton Luzern to collect bone marrow from the iliac crest during routine surgery ( $n=3$; average age 29.7 years). Bone marrow aspirate was diluted in $3.8 \%$ sodium citrate and $1 \mathrm{x}$ phosphate buffered saline (PBS) and filtered through a $100 \mu \mathrm{m}$ cell strainer (Falcon, BD Bioscience, Franklin Lakes, NJ, USA). Mononuclear cells fraction was isolated by centrifugation at $800 \mathrm{~g}$ for $20 \mathrm{~min}$ in a Leucosep tube (Greiner, Langenthal, Switzerland) over Ficoll gradient (density $1.077 \mathrm{~g} / \mathrm{mL}$; GE Healthcare, Glattbrugg, Switzerland). Cells were washed with PBS, centrifuged at $400 \mathrm{~g}$ and re-suspended in PBS, then counted using trypan blue dye (C-Chip Typ Neubauer, Zeiss, Jena, Germany). Cells were placed in a T150 tissue culture flask in NH-Expansion medium (Miltenyi, Bergisch Gladbach, Germany) at $37^{\circ} \mathrm{C}$ in a humid atmosphere containing $5 \%$ $\mathrm{CO}_{2}$. After $48 \mathrm{~h}$ non-adherent cells were discarded, whereas adherent cells were cultured in DMEM/F12 + GlutaMAX, supplemented with $10 \%$ foetal bovine serum (FBS), (100 units $/ \mathrm{mL})$ penicillin / $(100 \mu \mathrm{g} / \mathrm{mL})$ streptomycin, $2.5 \mathrm{ng} / \mathrm{mL}$ Amphotericin B (all Gibco/Invitrogen, Basel, Switzerland) and $5 \mathrm{ng} / \mathrm{mL}$ recombinant basic FGF-2 (Peprotech, London, UK) with medium changed 3 times per week. At $70 \%$ confluence, cells were harvested by dissociation with $0.05 \%$ trypsin and expanded to another passage in T300 flasks until required cell numbers were obtained. MSCs (passages 3 and 4) were then directly used in three dimensional cultures or cryopreserved in liquid nitrogen.

\section{Isolation of nucleus pulposus cells from bovine caudal discs}

Nucleus pulposus cells (bNPC) were derived from fresh caudal IVDs (6-12 months old) of bovine tails obtained from a local abattoir. NP tissue was dissected and digested initially in $0.19 \%$ pronase (Roche, Basel, Switzerland) solution for $1 \mathrm{~h}$ with a subsequent $14 \mathrm{~h}$ digestion in $0.4 \%$ collagenase II (Worthington, Lakewood, NJ, USA) solution in Dulbecco's Modified Eagles Medium (DMEM, Gibco) containing $10 \% \mathrm{FBS}$ and antibiotics. The digested tissue / cell suspension was passed through a $100 \mu \mathrm{m}$ cell strainer to remove tissue debris and cell count and viability were determined using trypan blue assay and haemocytometer cell counting. Then the cells were pelleted by centrifugation at $400 \mathrm{~g}$ for $5 \mathrm{~min}$, after which they were transferred to three dimensional alginate culture.

\section{Three dimensional MSCs culture and coculture with bNPC}

MSCs and bNPC were encapsulated in three dimensional $1.2 \%$ alginate (Fluka, Basel, Switzerland) beads at a density of $4 \times 10^{6}$ cells $/ \mathrm{mL}$ (approximately $8 \times 10^{4}$ cells per bead) by dropping the alginate solution through a $22 \mathrm{G}$ needle into a $0.9 \% \mathrm{NaCl}$ and $102 \mathrm{mM} \mathrm{CaCl}_{2}$ solution (Maldonado and Oegema, 1992). The beads were assigned to six separate groups: (1) Basal medium (BM), consisting of Dulbecco's Modified Eagle's Medium (DMEM) supplemented with 50 $\mu \mathrm{g} / \mathrm{mL}$ ascorbic acid, $2.5 \%$ FBS and ITS + (Gibco); (2) GDF, consisting of BM and $100 \mathrm{ng} / \mathrm{mL}$ rhGDF5; (3) GDF/ Dex, consisting of BM, $100 \mathrm{ng} / \mathrm{mL}$ rhGDF5 and $40 \mathrm{ng} / \mathrm{mL}$ dexamethasone; (4) Chondrogenic (TGF), consisting of $\mathrm{BM}, 10 \mathrm{ng} / \mathrm{mL}$ TGF $\beta 1$ and $40 \mathrm{ng} / \mathrm{mL}$ dexamethasone; (5) $\mathrm{NPC}$, an indirect coculture of $\mathrm{bNPC}$ and MSC, ratio $1: 1$ in $\mathrm{BM}$, where bNPC were grown in cell culture inserts with $0.4 \mu \mathrm{m}$ high pore density PET membranes (BD Falcon); (6) GDF/NPC, an indirect coculture as described above 
Table 1. Human genes used in quantitative RT-PCR. ( $F=$ Forward, $R=$ Reverse).

\begin{tabular}{|c|c|c|}
\hline Gene & Primer nucleotide sequence (5' to 3') & Product size (bp) \\
\hline \multirow[t]{2}{*}{ ACAN } & F - aggctatgagcagtgtgacg & 125 \\
\hline & R - gcacgccataggtcctga & \\
\hline \multirow[t]{2}{*}{ COL1A1 } & F - cctcctggctctcctggt & 114 \\
\hline & $\mathrm{R}$ - agggagaccgttgagtccat & \\
\hline \multirow[t]{2}{*}{ COL2A1 } & F - gaagtgctggtgctcgtg & 125 \\
\hline & $\mathrm{R}$ - ggcctctccttgctcacc & \\
\hline \multirow[t]{2}{*}{ 18S rRNA } & F - cgatgcggcggcgttatt & 198 \\
\hline & R - tctgtcaatcctgtcgtccgtgtcc & \\
\hline
\end{tabular}

Table 2. Human genes used with TaqMan $@$ quantitative RT-PCR method. ( $F=$ Forward, $R=$ Reverse). Gene expression assays are from Applied Biosystems.

\begin{tabular}{llr}
\hline & Primer nucleotide sequence (5' to 3') or Gene Expression & \\
Gene & Assay number & Product size (bp) \\
\hline COLXA1 & F - acgctgaacgataccaaatg & 101 \\
& R - tgctatacctttactctttatggtgta & \\
\hline
\end{tabular}

Probe (5'FAM/3'TAMRA) - actacccaacaccaagacacagttcttcattcc

\begin{tabular}{|c|c|}
\hline CA12 & Hs_00154221_m1 \\
\hline FOXF1 & Hs_00230962_m1 \\
\hline KRT19 & Hs_00761767_s1 \\
\hline SOX9 & Hs_00165814_m1 \\
\hline 18S rRNA & $4310893 \mathrm{E}$ \\
\hline
\end{tabular}

in BM containing $100 \mathrm{ng} / \mathrm{mL}$ rhGDF5. For groups (5) and (6) 12-well plates were used, with beads containing MSCs placed at the bottom of the well and beads containing bNPC placed into the culture well insert as previously illustrated (Gantenbein-Ritter et al., 2011). All groups were incubated at normal (20\%) or low (2\%) oxygen tension (total of 12 groups) and sampled at days $0,7,14$ and 28.

\section{RNA and protein isolation, cDNA synthesis and real time PCR}

RNA was isolated from alginate beads homogenised (Dispomix) in lysis buffer using Aurum Total Mini Kit (Bio-Rad, Basel, Switzerland) and further following the manufacturer's instructions, including a DNase treatment step. Total RNA $(\leq 500 \mathrm{ng})$ was used to synthesise cDNA utilising VILO cDNA Synthesis Kit (Invitrogen) in a reaction volume of $20 \mu \mathrm{L}$, after which cDNA was diluted 1:10 with RNAse-free water and stored at $-20{ }^{\circ} \mathrm{C}$. The diluted cDNA $(5 \mu \mathrm{L})$ was mixed with the PCR reaction solution (IQ SYBR Green Supermix, Bio-Rad) containing $0.25 \mu \mathrm{M}$ specific primers for $18 \mathrm{~S}$ rRNA, aggrecan (ACAN), collagen type I (COL1A1), and collagen type II (COL2A1) (Table 1). Reactions $(25 \mu \mathrm{L})$ were carried out in triplicates in a real time thermal cycler CFX96 (Bio-Rad). Specificity of the amplification products was controlled by performing a melting curve analysis after each reaction. For SOX9, collagen type X (COL10A1) and the potential NP cell differentiation markers cytokeratin 19 (KRT19), forkhead box F1 (FOXF1), and carbonic anhydrase 12 (CA12), TaqMan ${ }^{\circledR}$ method was applied using Gene Expression Master Mix, Gene Expression Assays (both from Applied Biosystems, Rotkreuz, Switzerland) and primers/probes listed in Table 2. PCR was performed with the GeneAmp 7500 Real Time PCR instrument (Applied Biosystems) under standard thermal conditions. Gene expression was calculated by the $2^{-\Delta \Delta \mathrm{Ct}}$ method (Livak and Schmittgen, 2001), normalizing data to $18 \mathrm{~S}$ rRNA as the endogenous control. The endogenous control was selected based on pilot experiments that confirmed the stability of this housekeeping gene under the different experimental conditions (data not shown). Additionally, the relative

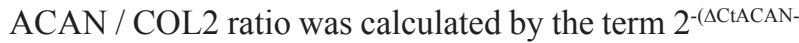
${ }_{\Delta \mathrm{CtCOL} 2)}$ (Mwale et al., 2004; Gantenbein-Ritter et al., 2011).

\section{Protein isolation and immunoblotting}

Protein was isolated from the lysates used for RNA isolation by pooling the Aurum column flow-through and first low stringency washing solution, precipitating for at least 14 
h at $-20{ }^{\circ} \mathrm{C}$, centrifugation at $15,000 \mathrm{~g}$ for $15 \mathrm{~min}$, washing with $70 \%$ ethanol and finally re-suspending the pellet in Lämmli sample application buffer. These samples were boiled at $99^{\circ} \mathrm{C}$ for $10 \mathrm{~min}$, separated by $10 \%$ SDS-PAGE, and transferred to a $0.45 \mu \mathrm{m}$ nitrocellulose membrane by wet electro-transfer (Bio-Rad); membranes were blocked in $5 \%$ bovine serum albumin in PBS and incubated with monoclonal antibodies against aggrecan (1:1000, AHP0022, Biosource, Nivelles, Belgium) or collagen type II (1:200; II-II6B3) and actin (1:1000, JLA20-s), (both from Developmental Studies Hybridoma Bank, University of Iowa, Ames, USA) overnight at $4{ }^{\circ} \mathrm{C}$. Then membranes were washed three times in PBS, incubated with goat antimouse horseradish peroxidase conjugated IgG (Bethyl Inc., Luzern, Switzerland) for $1 \mathrm{~h}$ at $20^{\circ} \mathrm{C}$, washed again and developed with tetramethylbenzidine Small Particle HRP Membrane chromogenic substrate (BioFX, Luzern, Switzerland) or Chemiluminescence Kit for Horseradish Peroxidase (Applichem).

\section{Glycosaminoglycan and DNA quantification}

Glycosaminoglycan (GAG) accumulation was quantified with dimethylmethylene blue (DMMB) (Farndale et al., 1986) binding assay after overnight digestion of three alginate beads per sample at $60^{\circ} \mathrm{C}$ with $125 \mu \mathrm{g} / \mathrm{mL}$ papain in $5 \mathrm{mM} \mathrm{L}$-cysteine HCL, $5 \mathrm{mM} \mathrm{Na}$-citrate, $150 \mathrm{mM} \mathrm{NaCl}$, $5 \mathrm{mM}$ EDTA. The GAG accumulation was determined by binding to DMMB blue (Fluka) at $\mathrm{pH} 1.5$ (for reduced alginate background) (Enobakhare et al., 1996). Within 5 min absorption was measured at $595 \mathrm{~nm}$ and quantified against chondroitin sulphate (Sigma-Aldrich, St. Louis, MO, USA) reference standards.

Total double stranded DNA was measured for each sample after papain digestion. The amount of DNA was determined using Quant-iT ds HS DNA Assay Kit (Molecular Probes, Invitrogen, Basel, Switzerland) and Qubit fluorometer (Invitrogen). All test groups were analysed in triplicates.

\section{Immunohistochemistry and histological analysis}

Beads were harvested after 28 days of culture in the different media, in normoxic and hypoxic cultures, fixed in $70 \%$ methanol, embedded in OCT Tissue Tek (Miles Laboratories, Inc., Elkhart. IN, USA) compound for $30 \mathrm{~min}$ and then frozen at $-80{ }^{\circ} \mathrm{C}$. Constructs were subsequently cryosectioned at $30 \mu \mathrm{m}$ thickness using a cryostat (CM 1850, Leica).

Immunohistochemical analysis was used to detect collagen type II and cytokeratin 19 accumulation. Endogenous peroxidases were quenched by $3 \% \mathrm{H}_{2} \mathrm{O}_{2}$ in $0.1 \mathrm{mM} \mathrm{CaCl}_{2}$ at room temperature for $10 \mathrm{~min}$, and washed with $0.1 \mathrm{mM} \mathrm{CaCl}_{2}$. Before incubation with anti-collagen type II antibody, sections were pre-treated for $40 \mathrm{~min}$ with $2500 \mathrm{U} / \mathrm{mL}$ hyaluronidase (Sigma-Aldrich) in $0.1 \mathrm{mM}$ $\mathrm{CaCl}_{2}$ at $37^{\circ} \mathrm{C}$. Non-specific background was blocked with PBS containing $1 \mathrm{mg} / \mathrm{mL} \mathrm{BSA}, 10 \%$ FBS and $0.1 \%$ Triton (Applichem) for $1 \mathrm{~h}$. Sections were incubated overnight at $4{ }^{\circ} \mathrm{C}$ with monoclonal mouse anti-collagen type II antibody (1:20; II-II6B3, Development Studies Hybridoma Bank) and cytokeratin $19(1: 500 ; 628501$, BioLegend) in blocking solution. After washing with $0.1 \mathrm{mM} \mathrm{CaCl}_{2}$, sections were incubated with a secondary biotinylated goat anti-mouse antibody (1:200; B0529, Sigma-Aldrich), and then with streptavidin-peroxidase polymer (1:200; S2438, Sigma) for $45 \mathrm{~min}$ at room temperature. Collagen type II and cytokeratin 19 were visualised by reaction with $0.075 \%$ solution of 3-amino-9-ethylcarbazole (AEC, Applichem) in $0.01 \% \mathrm{H}_{2} \mathrm{O}_{2}$. Sections were mounted with $70 \%$ Glycerol (Applichem) and examined by light microscopy.

Alternatively, for CA12 immunohistochemistry, beads were fixed in $70 \%$ methanol and embedded in paraffin. Sections were deparaffinised, treated with $3 \%$ hydrogen peroxide in methanol for $30 \mathrm{~min}$ and then with heated $(95$ $\left.{ }^{\circ} \mathrm{C}\right)$ citrate buffer ( $10 \mathrm{mM}$ sodium citrate, $0.05 \%$ Tween 20 , $\mathrm{pH}$ 6.0) for $15 \mathrm{~min}$ for antigen retrieval. Then they were blocked with $5 \%$ normal horse serum for $1 \mathrm{~h}$, and were incubated with rabbit anti-CA12 precursor antibody (cat. no. HPA008773, $0.04 \mathrm{mg} / \mathrm{mL}$, Prestige Antibodies, SigmaAldrich) at a 1:60 dilution over night at $4{ }^{\circ} \mathrm{C}$. Negative control sections were incubated without primary antibody. Biotinylated secondary anti-rabbit antibody (dilution 1:200; Vectastain ABC-kit Elite, Vector Laboratories, Burlingame, CA, USA) was applied, followed by ABC complex, and chromogen development using diaminobenzidine (DAB Kit, cat. no. SK-4100, Vector Laboratories). Sections were counterstained with Mayer's haematoxylin.

Histological detection of GAG accumulation was carried out by Alcian Blue staining. Sections were stained overnight with $0.4 \%$ alcian blue dissolved in $0.01 \% \mathrm{H}_{2} \mathrm{SO}_{4}$ (Applichem) and $0.5 \mathrm{M}$ guanidine hydrochloride (Fluka). Next, sections were washed for $30 \mathrm{~min}$ in $40 \%$ DMSO and $0.05 \mathrm{M} \mathrm{MgCl}_{2}$ (both from Applichem), mounted with $70 \%$ Glycerol and examined by light microscopy.

\section{Statistical analysis}

Wilcoxon non-parametric test for dependent data (PASW Statistics v.18) was used to compare gene expression, GAG and DNA. A significance value of $p<0.05$ was specified. Data from three human donors, each run in triplicate samples, are presented. Values are reported as mean $\pm \mathrm{SD}$.

\section{Results}

\section{Chondrogenic gene expression}

The mRNA expression of aggrecan was near the detection limit in normoxic control cultures (BM group) at early time points, which made the normoxic control group unsuitable as the reference group for data normalisation. Gene expression results were therefore expressed relative to the normoxic chondrogenic (TGF/Dex) group, which showed a robust expression of aggrecan already at day 7 ; this allowed for more reliable and accurate calculation. In the TGF/ Dex group, both in normoxia and hypoxia, human MSCs in three-dimensional alginate culture showed a trend of time-dependent increase of all tested chondrogenic genes except collagen type I (Fig. 1A-D). In normoxic cultures, the GDF/Dex group showed highest aggrecan expression at day 7, whereas at later time points the levels of the TGF/ Dex group were highest (200 fold up-regulation on day 28 compared to day 7) (Fig. 1A). Hypoxic culture increased aggrecan gene expression compared to the corresponding 


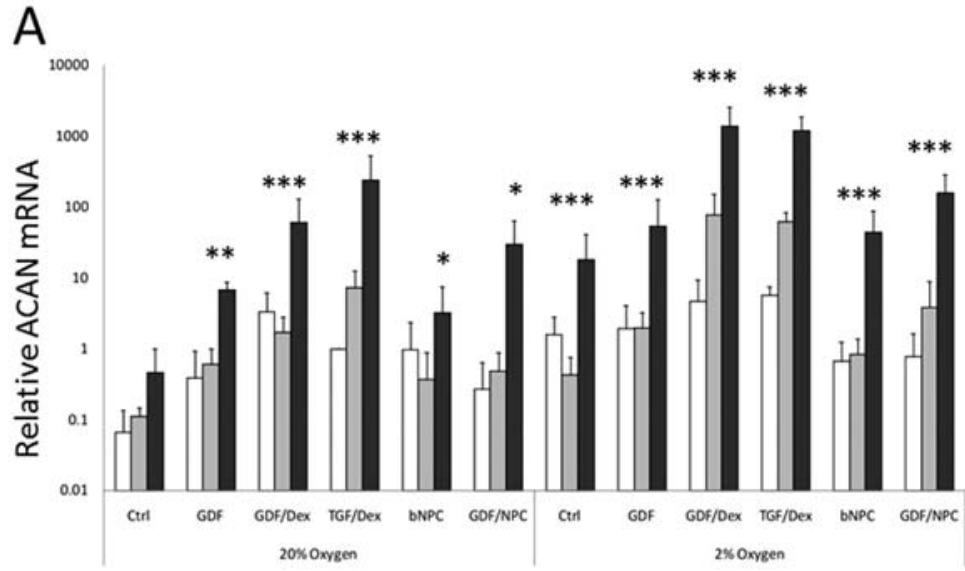

Day $7 \square$ Day $14 \square$ Day 28

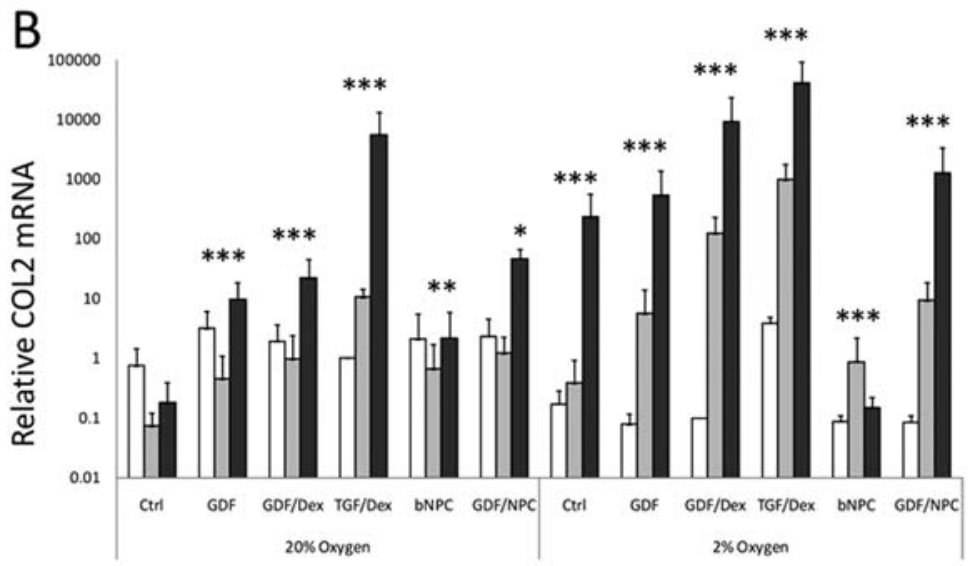

C

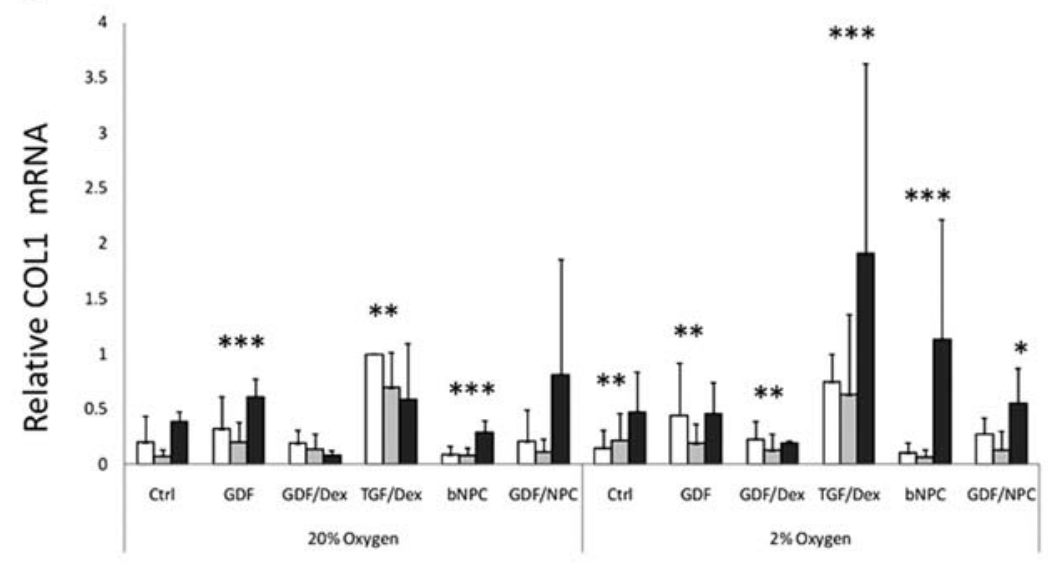

\section{Day $7 \quad$ Day 14 Day 28}

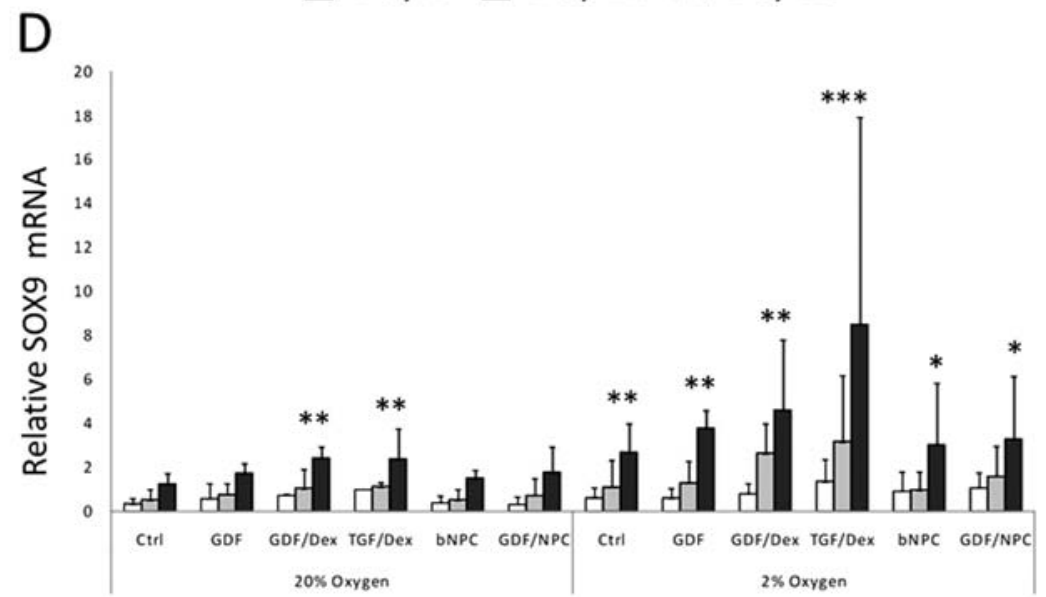

Figure 1. Comparison of chondrogenic gene expression between normoxic (20\% $\left.\mathrm{O}_{2}\right)$ and hypoxic $\left(2 \% \mathrm{O}_{2}\right)$ conditions of MSCs in alginate bead cultures. Analyses were conducted after 7, 14 and $28 \mathrm{~d}$ of culture. Expression of (A) aggrecan, (B) collagen type II, (C) collagen type I, and (D) Sox9 was normalised to $18 \mathrm{~S}$ rRNA and to the normoxic TGF/Dex group at day 7. Data represent mean $\pm \mathrm{SD} ;{ }^{*} p$ $<0.05$ vs. normoxic control group at respective time point. 

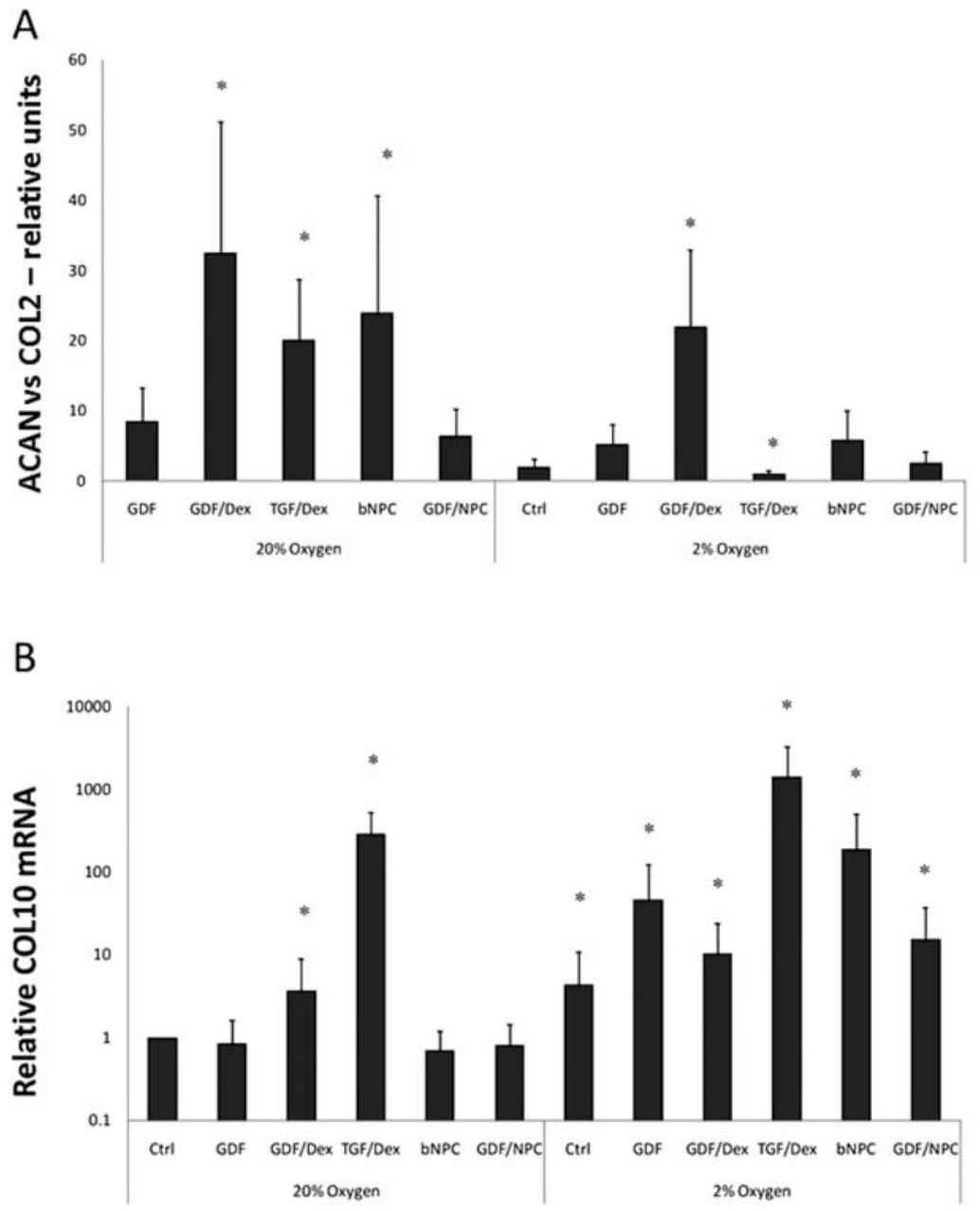

Figure 2. (A) Aggrecan to collagen type II expression ratio and (B) collagen type X gene expression of MSCs in alginate bead cultures. Normoxic $\left(20 \% \mathrm{O}_{2}\right)$ and hypoxic $\left(2 \% \mathrm{O}_{2}\right)$ conditions at $28 \mathrm{~d}$ of culture are shown. Expression was normalised to $18 \mathrm{~S}$ rRNA and to the normoxic control group. Data represent mean $\pm \mathrm{SD} ;{ }^{*} p<0.05$ vs. normoxic control group.

normoxic culture in all groups except the bNPC group at early time points. The hypoxic GDF/Dex and TGF/Dex groups demonstrated most increased aggrecan mRNA levels throughout culture with almost 1400 and 1200 fold induction at $28 \mathrm{~d}$. All groups apart from the normoxic (day 7 and day 14) and hypoxic (day 7) bNPC and GDF/ NPC showed a significant difference $(p<0.05)$ compared to the normoxic BM group within the same time point. Collagen type II expression followed similar trends (Fig. 1B). In normoxia, no clear differences were observed at early time points, while a 5,000 fold induction was noted in the TGF/Dex group at day 28. Hypoxic culture led to increased collagen II expression at day 14 and day 28 in all groups except the bNPC group. With $>40,000$ fold increase at day 28, the TGF/Dex group in hypoxia showed the highest relative expression, followed by the GDF/Dex group in hypoxia with $>9,000$ fold induction. As with aggrecan, all groups apart from the bNPC group in normoxia (day 7) and hypoxia (day 28) and the GDF/ NPC group in normoxia (day 7 and day 14), showed a significant difference $(p<0.05)$ compared to the BM group in normoxia. Coculture with bNPC neither enhanced chondrogenic genes in normoxic nor in hypoxic conditions; however, in the presence of GDF5, chondrogenic profiles were slightly increased. The expression of collagen type I was highest in the TGF/Dex group in hypoxia and lowest in the GDF/Dex group both in normoxia and hypoxia by day 28 (Fig. 1C). At the level of chondrogenic regulation, the expression of Sox 9 was increased systemically in hypoxia with highest level (8.5 fold increase) in the hypoxic TGF/ Dex group at day 28 (Fig. 1D). With two fold induction in the hypoxic BM group the Sox9 levels were similar to the normoxic levels in TGF/Dex and GDF/Dex groups at day 28 of culture.

The aggrecan-to-collagen II mRNA expression ratio was assessed, since it had previously been reported that the ratio of GAG to hydroxyproline could be used to distinguish NP from cartilage tissue; specifically, a markedly higher ratio had been found for the NP compared to cartilage (Mwale et al., 2004). The ratio was measured at the gene expression level since (i) hydroxyproline values that are generally lower than GAG amounts were 

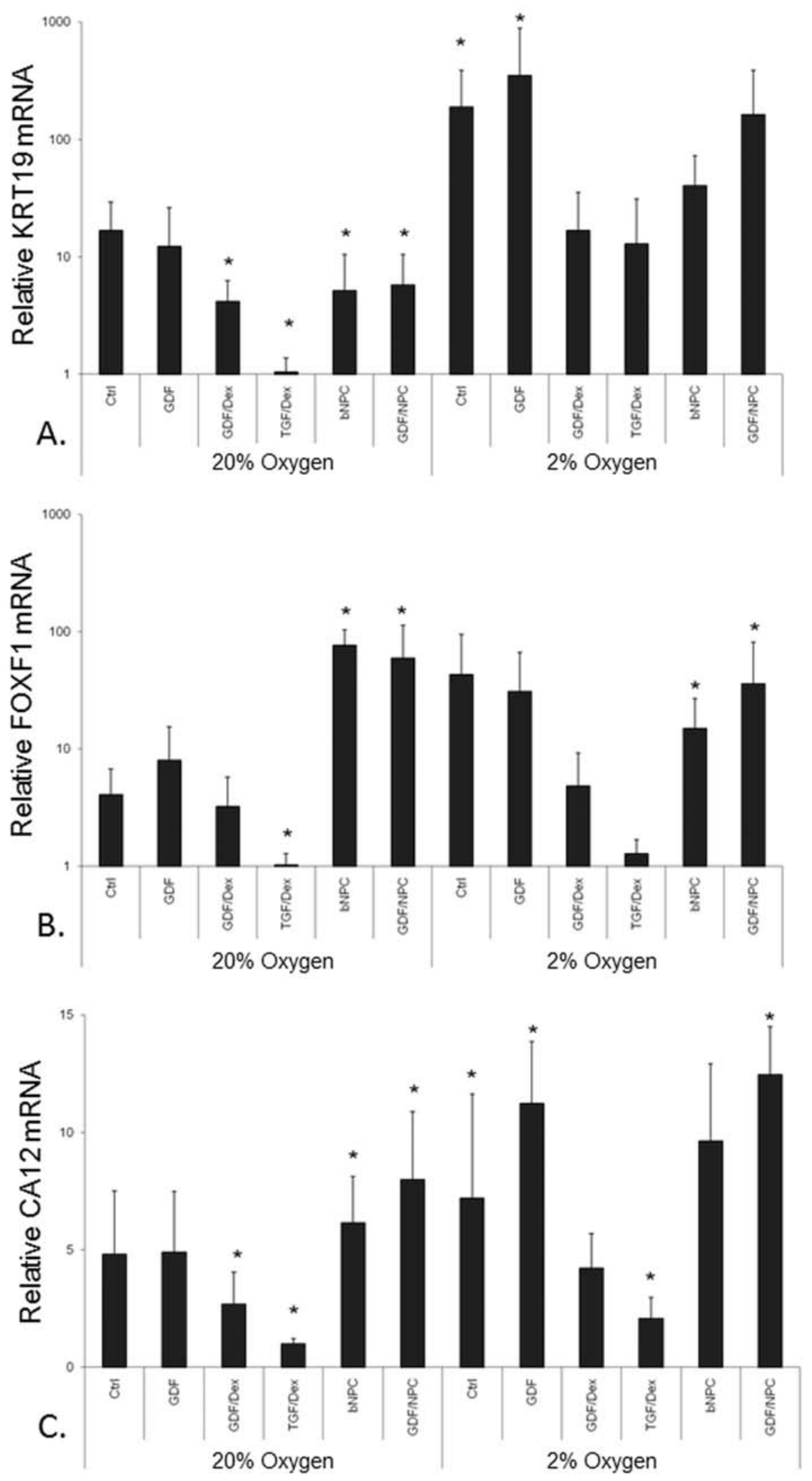

Figure 3. Gene expression of MSCs after $28 \mathrm{~d}$ of alginate bead culture. Expression of (A) cytokeratin 19, (B) forkhead box F1, and (C) carbonic anhydrase 12 was normalised to $18 \mathrm{~S} \mathrm{rRNA}$ and to the normoxic TGF/Dex group. Data represent mean $\pm \mathrm{SD} ;{ }^{*} p<0.05 v s$. normoxic control group. 


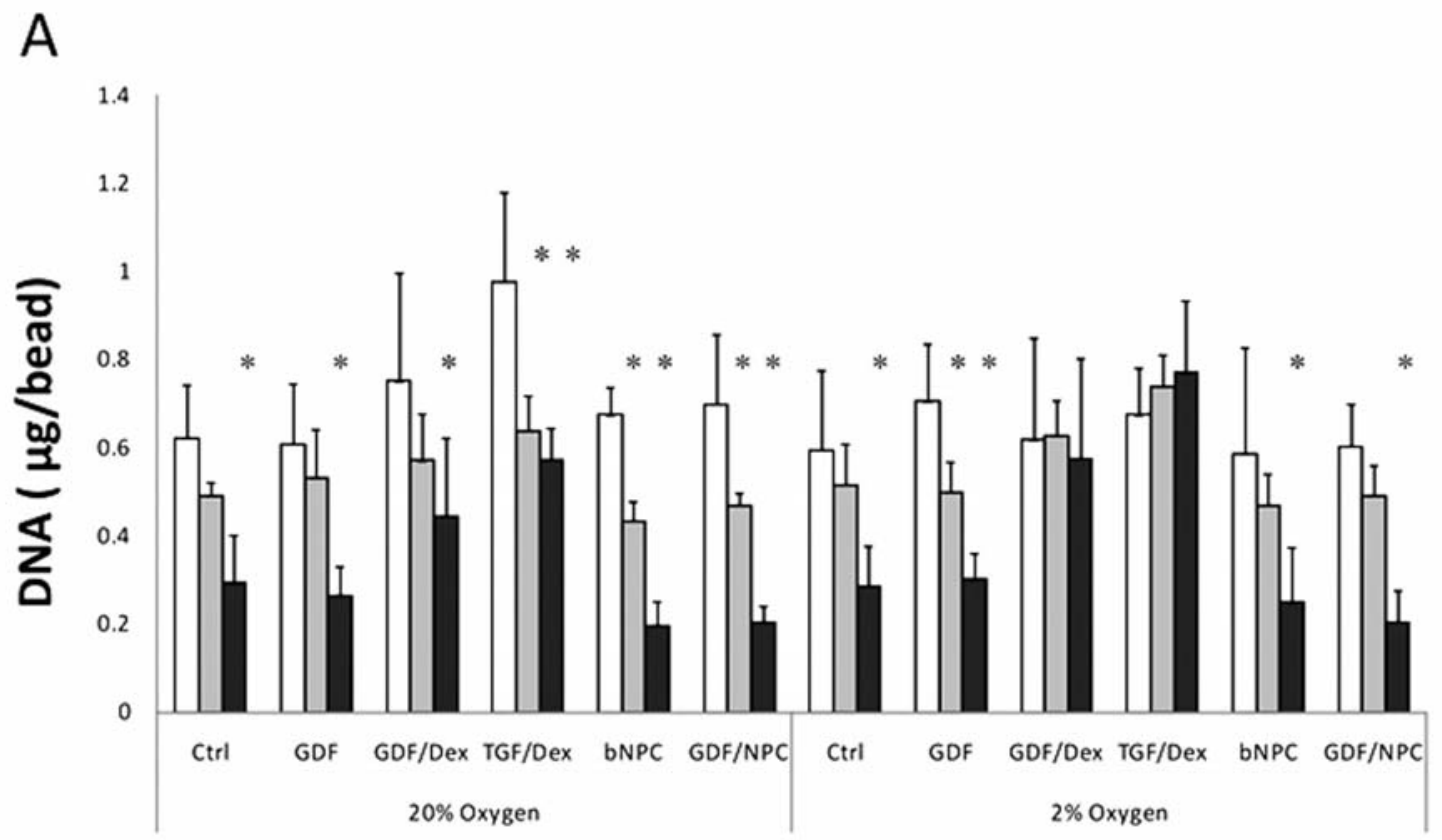

B

Day $7 \square$ Day $14 \square$ Day 28

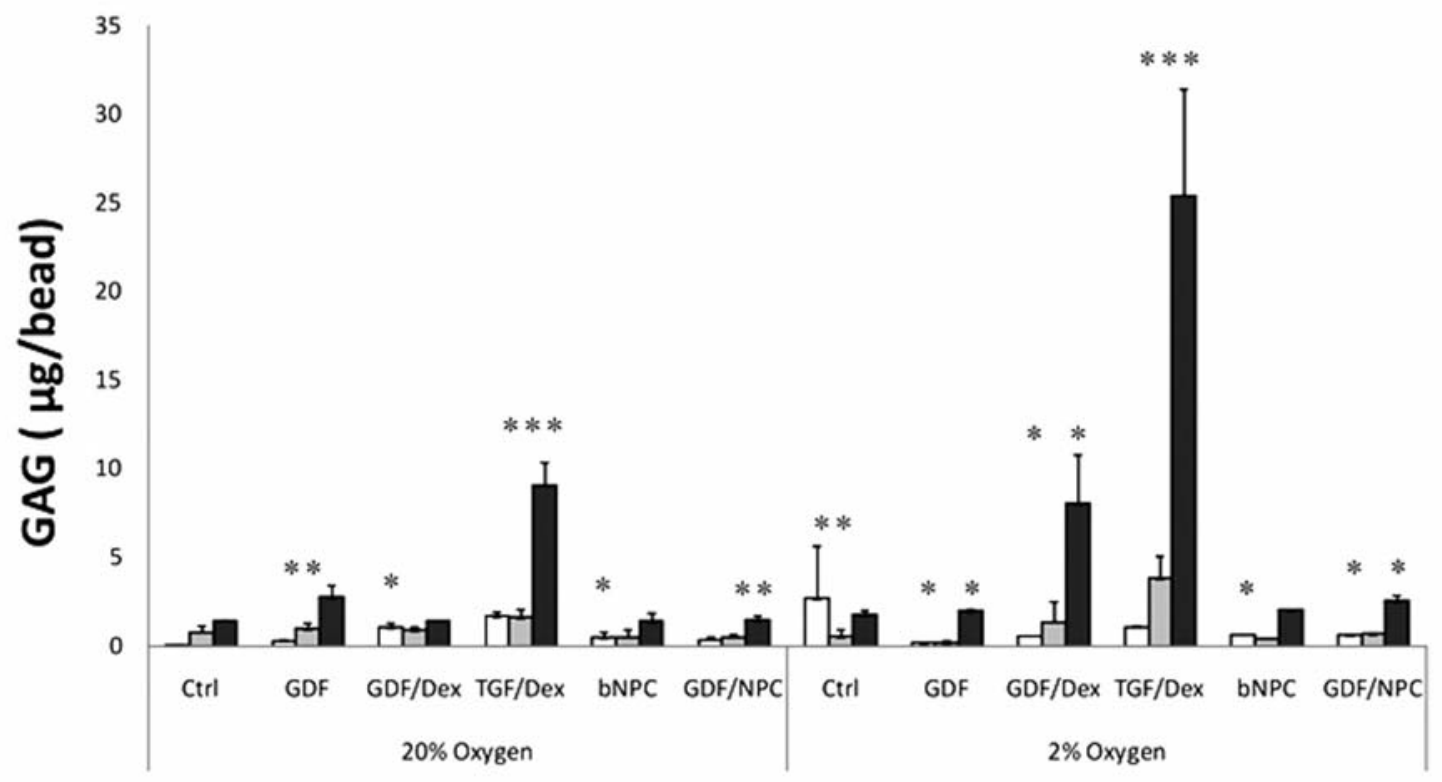

Figure 4. (A) Total DNA content and (B) glycosaminoglycan (GAG) accumulation in alginate bead MSC cultures in normoxic $\left(20 \% \mathrm{O}_{2}\right)$ and hypoxic $\left(2 \% \mathrm{O}_{2}\right)$ conditions. GAG and DNA assays were conducted after 7, 14 and 28 $\mathrm{d}$ of culture. Data represent mean $\pm \mathrm{SD} ;{ }^{*} p<0.05$ vs. normoxic control group at respective time point.

mostly below the limit of quantification of the assay and (ii) the expression of collagen type II was considered more relevant than the expression of total collagen. Relative

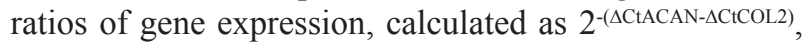
showed highest values (20:1-30:1) in the GDF/Dex groups both in normoxia and hypoxia compared to the lowest relative value of 1:1 in the hypoxic TGF/Dex group (Fig. 2A).

The expression of the hypertrophic marker collagen type $\mathrm{X}$ was most up-regulated in the TGF/Dex group compared to the normoxic BM group in both normoxia
( 300 fold) and hypoxia (1400 fold); generally all groups expressed more collagen type $\mathrm{X}$ mRNA at low compared to normal oxygen conditions (Fig. 2B).

\section{Gene expression of NP markers}

By day 28, cytokeratin 19 (KRT19) mRNA was expressed to highest extent in the control and GDF groups in hypoxic conditions; lowest expression was observed in the TGF/Dex group in normoxia. Generally, the KRT19 levels increased under hypoxia, whereas the presence of dexamethasone negatively influenced the levels of KRT19 

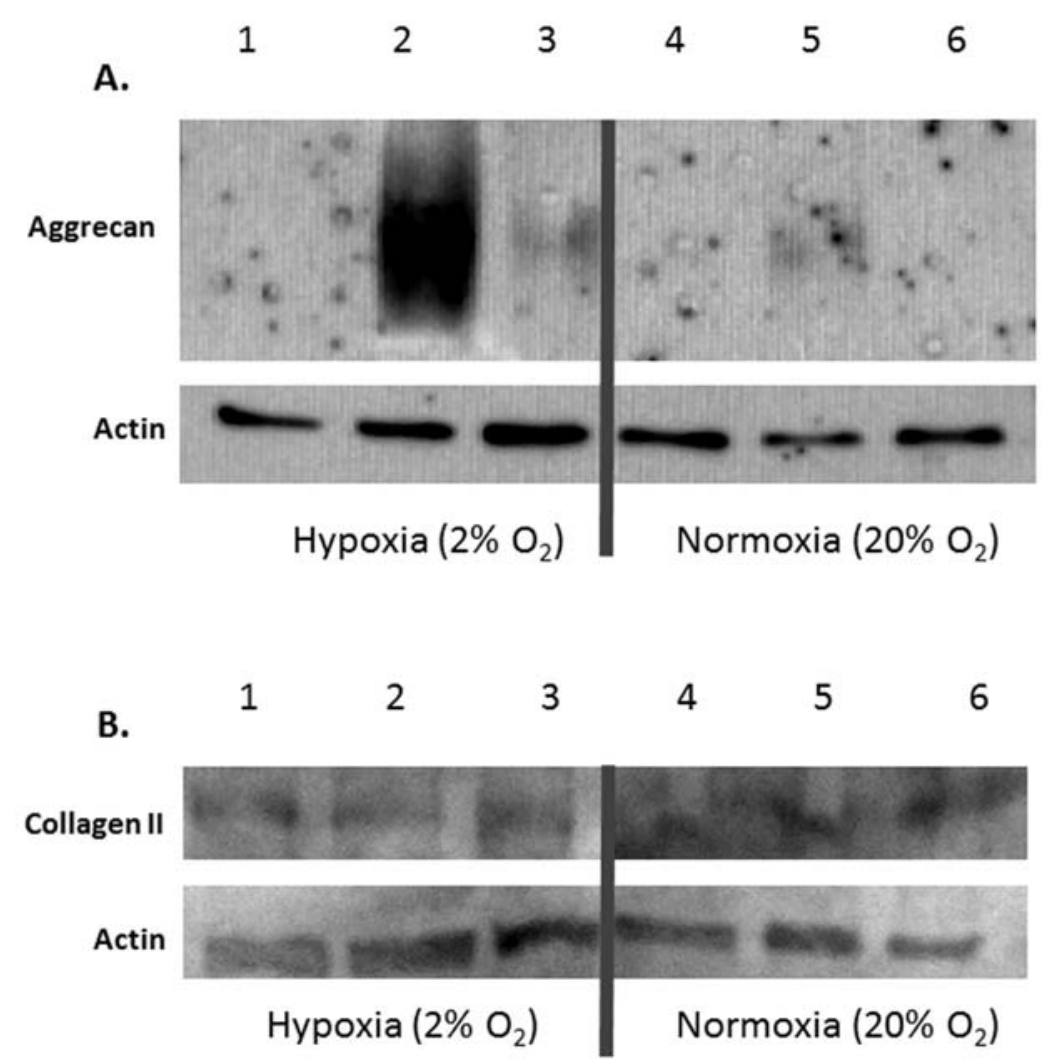

Figure 5. Immunoblotting of (A) aggrecan/actin and (B) collagen type II/actin in protein extracts from MSCs in alginate beads after $28 \mathrm{~d}$ of culture. Control (1 and 4), GDF/Dexa (2 and 5), and TGF/Dexa (3 and 6).

both in hypoxia and normoxia (Fig. 3A). Forkhead box F1 (FOXF1) mRNA was enhanced by coculture with bNPC and was significantly down-regulated in the chondrogenic TGF/Dex group (Fig. 3B). Similarly, carbonic anhydrase 12 (CA12) mRNA expression was also reduced by TGF/ Dex and to a lesser extent by GDF/Dex supplementation, whereas coculture with bNPC or hypoxic conditions appeared to increase the CA12 gene expression (Fig. 3C).

\section{Total GAG and DNA content}

In normoxia the total amount of DNA dropped over the four weeks culture time in all samples, while under hypoxia the DNA content remained stable in the GDF/Dex and TGF/ Dex groups over the same time (Fig. 4A).

The detection of solubilised GAG by DMMB chromogenic assay was time dependent and was highest in the TGF/Dex groups at day 28 (Fig. 4B). While hypoxia in the absence of growth factors did not induce GAG accumulation, there was a marked increase over normoxia in the TGF/Dex and GDF/Dex groups. Specifically, the overall accumulation of GAG in the TGF/Dex group after 28 days of culture showed a significant $(p<0.05)$ six-fold increase in normoxia and 18-fold increase in hypoxia, compared to the control group in normoxia. The hypoxic GDF/Dex group at the same time point showed a 5.5-fold increase compared to the control group; interestingly there was no increase in proteoglycan content in the GDF/Dex group under normal oxygen conditions.

\section{Matrix and marker protein accumulation}

Immunoblotting of the protein in the flow-through of RNA extraction lysates was used to detect aggrecan and collagen type II using monoclonal antibodies. Using this method, aggrecan was shown to be strongly expressed in the GDF/Dex group and collagen type II was detected in hypoxia, in the TGF/Dex and GDF/Dex groups (Fig. 5). Immunoblotting therefore confirmed the aggrecan-tocollagen II results from the RT-PCR and identified the strongest aggrecan producing sample at day 28 .

Histological staining of alginate bead sections with Alcian blue confirmed increased GAG accumulation under hypoxia at day 28 , with the GDF/Dex group showing stronger and more homogenous staining than the TGF/Dex group (Fig. 6, top panel). This was further corroborated by most intense immunostaining for aggrecan in the hypoxic GDF/Dex group, followed by the hypoxic TGF/Dex group (data not shown).

Immunohistological detection of collagen type II revealed most pronounced staining in sections of alginate beads cultured under hypoxia in the presence of GDF/Dex and especially TGF/Dex (Fig. 6, bottom panel). Furthermore, immunohistochemical staining also demonstrated enhanced expression of KRT19 protein in hypoxic cultures supplemented with growth factors and more intense CA12 immunoreactivity in hypoxic compared to normoxic cultures (Fig. 7). 

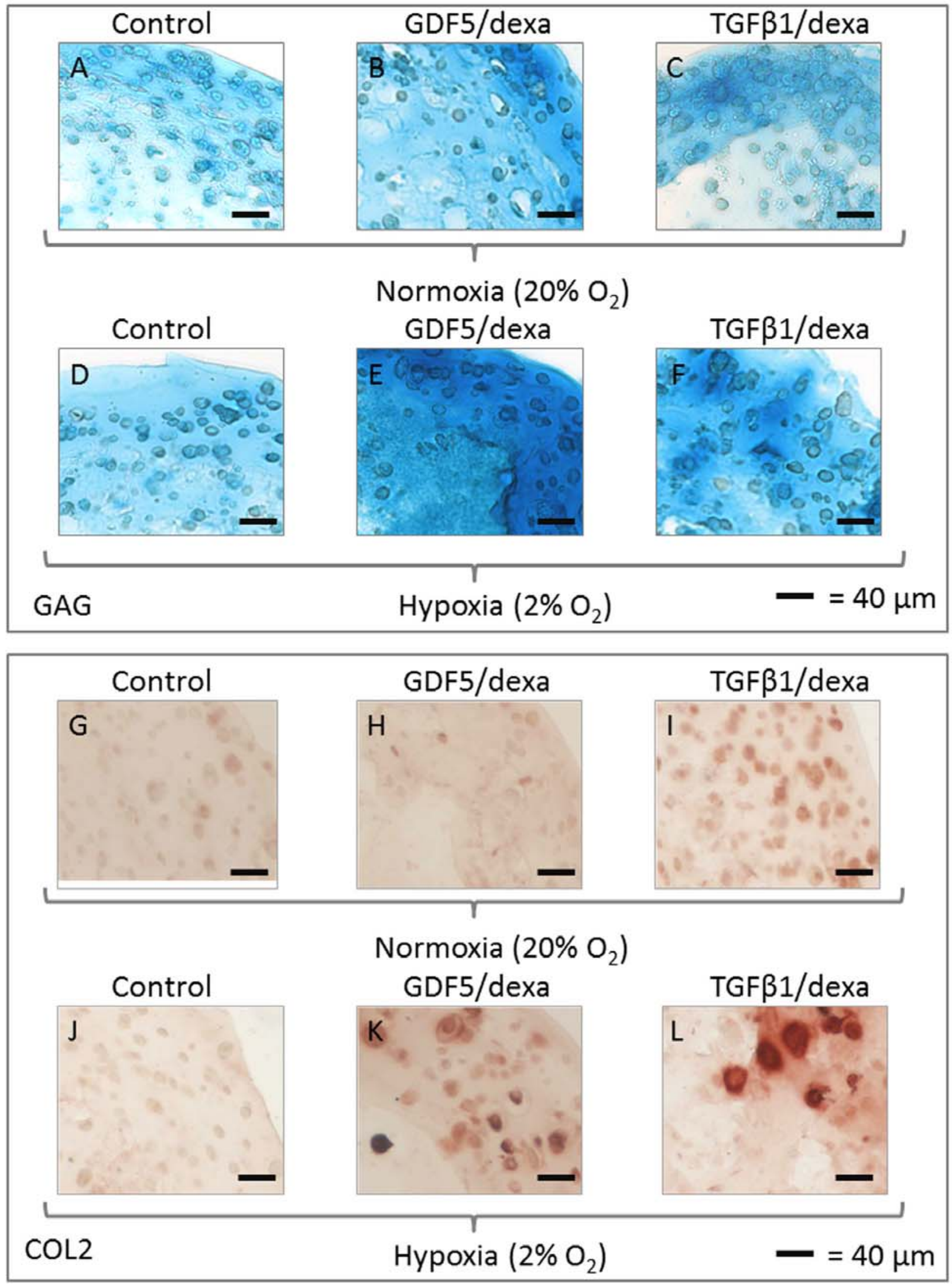

Figure 6. Alcian Blue staining of GAG (top panel) and collagen type II immunostaining (bottom panel) of MSCs in alginate beads. Beads were cultured: without growth factors, control (A, D, G and J), with GDF5/Dexa (B, E, H and $\mathrm{K})$, or with TGF/Dexa (C, F, I and L) supplementation under normoxic $\left(20 \% \mathrm{O}_{2}\right)$ or hypoxic $\left(2 \% \mathrm{O}_{2}\right)$ conditions for $28 \mathrm{~d}$. Scale bar $=40 \mu \mathrm{m}$. 

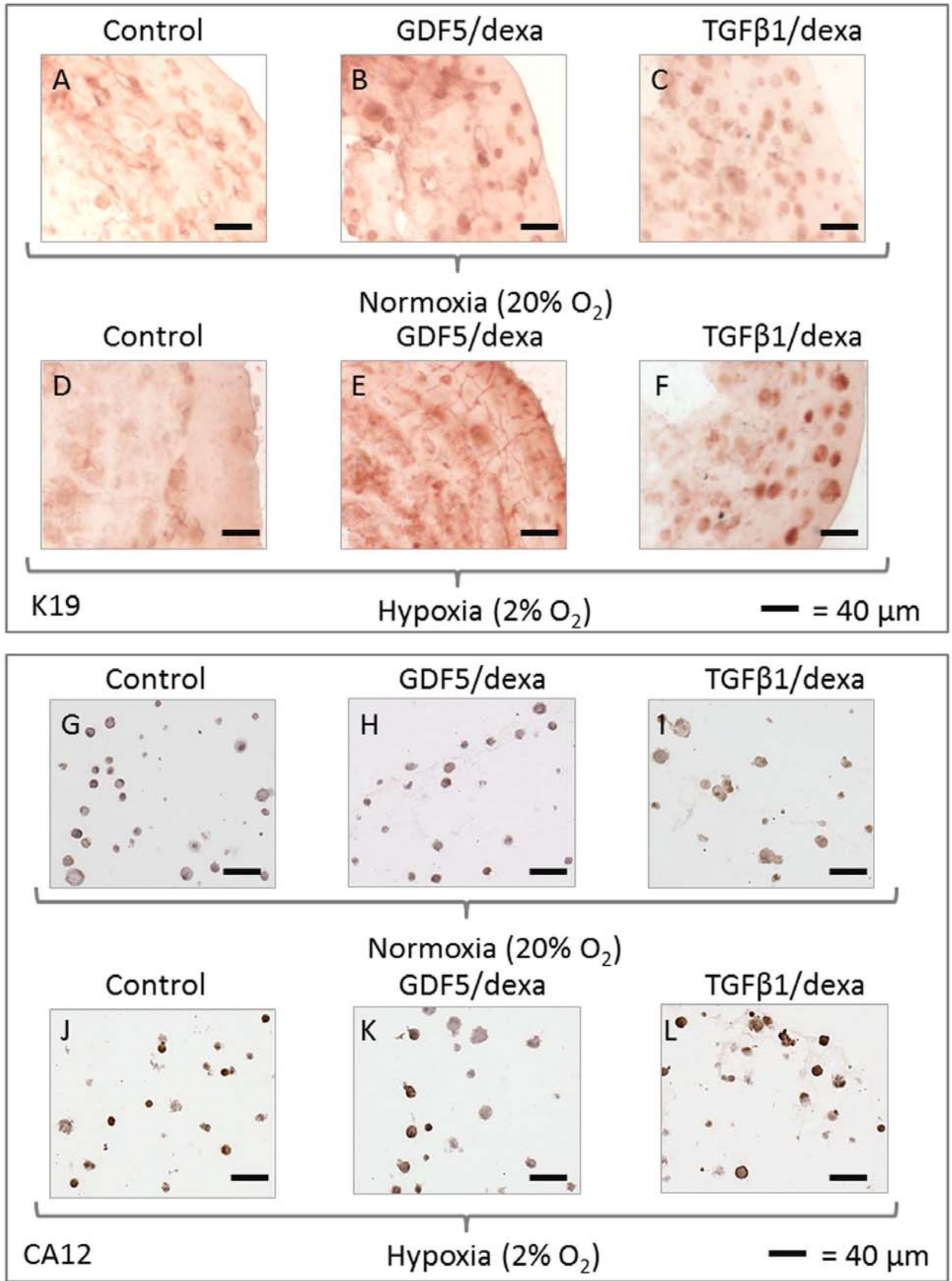

Figure 7. Immunostaining for Cytokeratin 19 (top panel), and carbonic anhydrase 12 (bottom panel) of MSCs in alginate bead sections. Beads were cultured: without growth factors, control (A, D, G and J), with GDF5/Dexa (B, E, $\mathrm{H}$ and $\mathrm{K})$, or with TGF/Dexa (C, F, I and L) supplementation under normoxic $\left(20 \% \mathrm{O}_{2}\right)$ or hypoxic $\left(2 \% \mathrm{O}_{2}\right)$ conditions for $28 \mathrm{~d}$. Scale bar $=40 \mu \mathrm{m}$. 


\section{Discussion}

While standard procedures have been defined to induce a chondrogenic phenotype in MSCs, different stimuli have been suggested to be required for IVD-like differentiation. This study aimed (i) to compare hypoxia, growth factors and coculture for in vitro differentiation of human bone marrow derived MSCs and (ii) to evaluate gene expression markers for detecting IVD-like differentiation and separating it from chondrogenic differentiation.

With respect to the typical chondrogenic markers aggrecan, type II collagen, Sox 9, and glycosaminoglycans, TGF/Dex supplementation demonstrated the expected pronounced chondrogenic gene up-regulation and GAG accumulation. Treatment with GDF5/Dex showed similar effects, although with different collagen to aggrecan ratios, while hypoxic conditions generally enhanced the chondrogenic response. These beneficial effects of low oxygen tension in terms of chondrogenic or NP-like differentiation of MSCs are in agreement with previously described data and are likely to reflect the in vivo situation that is characterised by physiologically low oxygen concentration in NP and cartilaginous tissues (Risbud et al., 2004; Baumgartner et al., 2010; Markway et al., 2010).

For differentiation towards chondrogenic and NP-like cells GDF5 application shows several advantages over TGF- $\beta$, including the depressed expression of collagen type I and collagen type X. Collagen type $\mathrm{X}$ is a marker of the hypertrophic phenotype; hence a suppression of type X collagen expression would be of advantage for the development and preservation of a chondrogenic or disc-like phenotype. Treatment of MSCs with TGF $\beta$ in vitro generally leads to a hypertrophic rather than a stable chondrogenic phenotype. This is associated with endochondral ossification and calcification processes (Pelttari et al., 2006; Pelttari et al., 2008). With respect to NP-like differentiation, the enhanced aggrecan to collagen II gene expression ratio is an additional benefit of GDF5 (Gantenbein-Ritter et al., 2011); the proportion of glycosaminoglycan to collagen is markedly higher in the NP than in cartilage and can provide a reliable measure to differentiate between these two tissues (Mwale et al., 2004). The elevated proteoglycan (or specifically aggrecan) to collagen II ratios in cultures supplemented with GDF5 compared to TGF- $\beta$ were also observed at the protein level; the slight divergences between gene and protein expression patterns may be attributed to the different sensitivities between mRNA and protein detection methods, different post-translational regulations, and/or delayed protein compared to mRNA synthesis. The chondrogenic potential of GDF5 has previously been demonstrated (Bai et al., 2004; Feng et al., 2008). Furthermore, due to its beneficial effects on both NP cells and MSCs GDF5 has been proposed as a promising factor for NP tissue engineering (Yang and Li, 2009).

Although the phenotype of IVD and in particular NP cells is closely related to the chondrocytic phenotype and the cellular environment and extracellular matrix composition are similar between chondrocytes and NP cells, distinct differences have been described. Genes preferably expressed in the NP may be valuable for monitoring expression changes in MSCs in response to environmental stimuli that are likely to induce an NPlike phenotype. It is hypothesised that molecules that are expressed significantly more highly in native disc cells compared to chondrocytes would be up-regulated during the course of NP-like in contrast to chondrogenic differentiation. Cytokeratin-19 was identified as an NP marker in rat cells and was demonstrated to be expressed also in human NP cells (Lee et al., 2007; Rutges et al., 2010; Weiler et al., 2010). Results of the present study indicate that low oxygen tension can induce KRT19 expression in MSCs. Certain cytokeratins including KRT19 have been identified as notochordal cell markers (Weiler et al., 2010). However there is a body of evidence showing that all NP cells are of identical origin (Risbud et al., 2010); hence the presence of KRT19 also in non-notochordal NP cells is in agreement with the latter hypothesis. Furthermore the gene expression differences of 2-3 orders of magnitude between the normoxic TGF $\beta /$ Dex treated and hypoxic cultured MSCs may allow indications about their differentiation state. Furthermore, immunohistochemistry confirmed the mRNA data of increased expression of KRT19 under hypoxia in the GDF/Dex and TGF/Dex groups, although not in the control group.

Similar to the KRT19 mRNA expression, the levels of forkhead box F1 (FOXF1) and carbonic anhydrase 12 (CA12), two other potential molecular markers for NP cells, were also decreased in response to the standard chondrogenic supplements TGF- $\beta /$ Dex. FOXF1 and CA12 were previously reported to be expressed at increased levels in human IVD in comparison to articular cartilage cells (Minogue et al., 2010). Interestingly, indirect coculture with NPC induced an up-regulation of these genes, suggesting that soluble factors released by the NPC may promote an NP-like phenotype in MSCs (Kim et al., 2009; Gantenbein-Ritter et al., 2011). Interaction between NPC and MSC by paracrine stimulation has been described before, although higher numbers of NPC may be necessary to significantly induce a chondrogenic phenotype in coculture without cell-cell contact (Yang et al., 2008). FOXF1 is a member of the forkhead box transcription factors. It has been identified as a mesenchyme-specific marker with essential functions in organ development and repair and in mesenchymal cell migration (Mahlapuu et al., 1998; Malin et al., 2007).

CA12 expression was also increased by low oxygen conditions. Immunohistochemistry confirmed the enhanced levels of CA12 protein under hypoxia in all experimental groups. This is consistent with findings of hypoxia induced carbonic anhydrase up-regulation in tumour cells (Wykoff et al., 2000; Ivanov et al., 2001). In particular, hypoxiainducible CA9 and CA12 have been shown to promote cell survival and growth through maintenance of the intracellular $\mathrm{pH}$ (Chiche et al., 2009). Hypoxia-induced CA12 mediated $\mathrm{pH}$ regulation may also play a major role in NP cell and MSC survival.

However, while this study provides further insight in the expression and regulation of these potential new NP marker genes during MSCs differentiation, the functional role of these molecules in IVD homeostasis requires further investigation. Moreover, although clear and significant 
trends are observed, the low number of donors is a limitation of this study.

An indirect coculture system was chosen in this study, which facilitates the recovery of the MSCs after culture for gene expression analysis. Coculture with NPC increased the expression of CA12 and FOXF1 and also moderately aggrecan and collagen II in MSC after 28 days at the mRNA level. Several recent studies have shown that coculture with NPC can induce an NP-like phenotype in MSC (Vadala et al., 2008; Miyamoto et al., 2010; Strassburg et al., 2010). Interactions between human NP cells and adipose tissue derived stem cells were also studied in indirect coculture, whereby chondrogenic differentiation of the adipose stem cells was achieved when both cell types were maintained in micromass culture (Lu et al., 2007). Moreover, MSC have been reported to enhance the metabolic activity of NP cells (Strassburg et al., 2010; Watanabe et al., 2010). This has implications for MSC-based regenerative therapy, where implanted stem cells may activate endogenous NP cells; while the latter in turn may promote differentiation of the regenerative stem cells (Yang et al., 2009; Miyamoto et al., 2010).

In conclusion, all the investigated stimuli - hypoxia, GDF5, and to lesser extent, NPC coculture - affect the gene expression profile of human bone marrow derived MSCs in three dimensional alginate culture by induction of markers associated with an NP-like phenotype. However, the different stimuli influence different genes, although additive responses can be observed, e.g. by GDF5 under hypoxia. This may have implications for (i) in vitro differentiation of MSCs towards an NP-like phenotype and (ii) stimulation of endogenous progenitor cells after therapeutic application of GDF5 for IVD regenerative therapy. Further studies, including direct comparison with native disc cells, will be required to evaluate the potential of MSCs derived from bone marrow and other tissues (e.g. adipose) to approach an IVD-like phenotype.

\section{Acknowledgements}

This study was supported by the Swiss Paraplegic Foundation (SPF) and the Swiss National Science Foundation (SNF grant \#320030-116818). We thank Nora Goudsouzian for support in immunohistochemistry, Dr. Angela Frotzler for her advice with statistics and Advanced Technologies and Regenerative Medicine, LLC, for a gift of rhGDF5.

\section{References}

Adams MA, Roughley PJ (2006) What is intervertebral disc degeneration, and what causes it? Spine 31: 21512161.

Bai X, Xiao Z, Pan Y, Hu J, Pohl J, Wen J, Li L (2004) Cartilage-derived morphogenetic protein-1 promotes the differentiation of mesenchymal stem cells into chondrocytes. Biochem Biophys Res Commun 325: 453460 .
Baumgartner L, Arnhold S, Brixius K, Addicks K, Bloch W (2010) Human mesenchymal stem cells: Influence of oxygen pressure on proliferation and chondrogenic differentiation in fibrin glue in vitro. J Biomed Mater Res A 93: 930-940.

Caplan AI. (1991) Mesenchymal stem cells. J Orthop Res 9: 641-650.

Chamberlain G, Fox J, Ashton B, Middleton J (2007) Concise review: mesenchymal stem cells: their phenotype, differentiation capacity, immunological features, and potential for homing. Stem Cells 25: 2739-2749.

Chiche J, Ilc K, Laferrière J, Trottier E, Dayan F, Mazure NM, Brahimi-Horn MC, Pouysségur J (2009) Hypoxia-inducible carbonic anhydrase IX and XII promote tumor cell growth by counteracting acidosis through the regulation of the intracellular $\mathrm{pH}$. Cancer Res 69: 358-368.

Enobakhare BO, BaderDL, LeeDA(1996)Quantification of sulfated glycosaminoglycans in chondrocyte/alginate cultures, by use of 1,9-dimethylmethylene blue. Anal Biochem 243: 189-191.

Farndale RW, Buttle DJ, Barrett AJ (1986) Improved quantitation and discrimination of sulphated glycosaminoglycans by use of dimethylmethylene blue 1 . Biochimica and Biophysica Acta 883: 173-177.

Felka T, Schäfer R, Schewe B, Benz K, Aicher WK (2009) Hypoxia reduces the inhibitory effect of IL-1beta on chondrogenic differentiation of FCS-free expanded MSC. Osteoarthritis Cartilage 17: 1368-1376.

Feng G, Wan Y, Balian G, Laurencin CT, Li X (2008) Adenovirus-mediated expression of growth and differentiation factor-5 promotes chondrogenesis of adipose stem cells. Growth Factors 26: 132-142.

Francis-West PH, Abdelfattah A, Chen P, Allen C, Parish J, Ladher R, Allen S, MacPherson S, Luyten FP, Archer CW (1999) Mechanisms of GDF-5 action during skeletal development. Development 126: 1305-1315.

Ganey T, Hutton WC, Moseley T, Hedrick M, Meisel HJ (2009) Intervertebral disc repair using adipose tissuederived stem and regenerative cells: experiments in a canine model. Spine 34: 2297-2304.

Gantenbein-Ritter B, Benneker L, Alini M, Grad S (2011) Differential response of Human Bone Marrow Stromal Cells to either TGF- $\beta 1$ or to rhGDF-5. Eur Spine J 20: 962-971.

Grad S, Alini M, Eglin D, Sakai D, Mochida J, Mahor S, Collin E, Dash B, Pandit A (2010) Cells and biomaterials for intervertebral disc regeneration. In: Synthesis lectures on tissue engineering (Athanasiou KA, ed), Morgan and Claypool Publishers, San Francisco, CA, pp 1-94.

Ivanov S, Liao SY, Ivanova A, Danilkovitch-Miagkova A, Tarasova N, Weirich G, Merrill MJ, Proescholdt MA, Oldfield EH, Lee J, Zavada J, Waheed A, Sly W, Lerman MI, Stanbridge EJ (2001) Expression of hypoxia-inducible cell-surface transmembrane carbonic anhydrases in human cancer. Am J Pathol 158: 905-919.

Kim DH, Kim SH, Heo SJ, Shin JW, Lee SW, Park SA, Shin JW (2009) Enhanced differentiation of mesenchymal stem cells into NP-like cells via $3 \mathrm{D}$ co-culturing with mechanical stimulation. J Biosci Bioeng 108: 63-67.

Lee CR, Sakai D, Nakai T, Toyama K, Mochida J, Alini M, Grad S (2007) A phenotypic comparison of 
intervertebral disc and articular cartilage cells in the rat. Eur Spine J 16: 2174-2185.

Le Maitre CL, Baird P, Freemont AJ, Hoyland JA (2009) An in vitro study investigating the survival and phenotype of mesenchymal stem cells following injection into nucleus pulposus tissue. Arthritis Res Ther 11: R20.

Leung VY, Chan D, Cheung KM (2006) Regeneration of intervertebral disc by mesenchymal stem cells: potentials, limitations, and future direction. Eur Spine J 15 Suppl 3: S406-S413.

Livak KJ, Schmittgen TD (2001) Analysis of relative gene expression data using real-time quantitative PCR and the 2(-Delta Delta C(T)) method. Methods 25: 402-408.

Lu ZF, Zandieh Doulabi B, Wuisman PI, Bank RA, Helder MN (2007) Differentiation of adipose stem cells by nucleus pulposus cells: configuration effect. Biochem Biophys Res Commun 359: 991-996.

Mahlapuu M, Pelto-Huikko M, Aitola M, Enerbäck S, Carlsson P (1998) FREAC-1 contains a cell-type-specific transcriptional activation domain and is expressed in epithelial-mesenchymal interfaces. Dev Biol 202: 183-195.

Maldonado BA, Oegema TR, (1992) Initial characterisation of the metabolism of intervertebral disc cells encapsulated in microspheres. J Orthop Res 10: 677 690.

Malin D, Kim IM, Boetticher E, Kalin TV, Ramakrishna S, Meliton L, Ustiyan V, Zhu X, Kalinichenko VV (2007) Forkhead box F1 is essential for migration of mesenchymal cells and directly induces integrin-beta3 expression. Mol Cell Biol 27: 2486-2498.

Markway BD, Tan GK, Brooke G, Hudson JE, CooperWhite JJ, Doran MR (2010) Enhanced chondrogenic differentiation of human bone marrow-derived mesenchymal stem cells in low oxygen environment micropellet cultures. Cell Transplant 19: 29-42.

Minogue BM, Richardson SM, Zeef LA, Freemont AJ, Hoyland JA (2010) Characterisation of the human nucleus pulposus cell phenotype and evaluation of novel marker gene expression to define adult stem cell differentiation. Arthritis Rheum 62: 3695-3705.

Miyamoto T, Muneta T, Tabuchi T, Matsumoto K, Saito H, Tsuji K, Sekiya I (2010) Intradiscal transplantation of synovial mesenchymal stem cells prevents intervertebral disc degeneration through suppression of matrix metalloproteinase-related genes in nucleus pulposus cells in rabbits. Arthritis Res Ther 12: R206.

Mwale F, Roughley P, Antoniou J (2004) Distinction between the extracellular matrix of the nucleus pulposus and hyaline cartilage: a requisite for tissue engineering of intervertebral disc. Eur Cell Mater 8: 58-63.

Paesold G, Nerlich AG, Boos N (2007) Biological treatment strategies for disc degeneration: potentials and shortcomings. Eur Spine J 16: 447-468.

Pelttari K, Winter A, Steck E, Goetzke K, Hennig T, Ochs BG, Aigner T, Richter W (2006) Premature induction of hypertrophy during in vitro chondrogenesis of human mesenchymal stem cells correlates with calcification and vascular invasion after ectopic transplantation in SCID mice. Arthritis Rheum 54: 3254-3266.
Pelttari K, Steck E, Richter W (2008) The use of mesenchymal stem cells for chondrogenesis. Injury 39 Suppl 1: S58-S65.

Pittenger MF, Mackay AM, Beck SC, Jaiswal RK, Douglas R, Mosca JD, Moorman MA, Simonetti DW, Craig S, Marshak DR (1999) Multilineage potential of adult human mesenchymal stem cells. Science 284: 143.

Richardson SM, Walker RV, Parker S, Rhodes NP, Hunt JA, Freemont AJ, Hoyland JA (2006) Intervertebral disc cell-mediated mesenchymal stem cell differentiation. Stem Cells 24: 707-716.

Richardson SM, Hoyland JA, Mobasheri R, Csaki C, Shakibaei M, Mobasheri A (2010) Mesenchymal stem cells in regenerative medicine: opportunities and challenges for articular cartilage and intervertebral disc tissue engineering. J Cell Physiol 222: 23-32.

Risbud MV, Albert TJ, Guttapalli A, Vresilovic EJ, Hillibrand AS, Vaccaro AR, Shapiro IM (2004) Differentiation of mesenchymal stem cells towards a nucleus pulposus-like phenotype in vitro: implications for cell-based transplantation therapy. Spine 29: 2627-2632.

Risbud MV, Schaer TP, Shapiro IM (2010) Toward an understanding of the role of notochordal cells in the adult intervertebral disc: From discord to accord. Dev Dyn 239: 2141-2148.

Rutges J, Creemers LB, Dhert W, Milz S, Sakai D, Mochida J, Alini M, Grad S (2010) Variations in gene and protein expression in human nucleus pulposus in comparison with annulus fibrosus and cartilage cells: potential associations with aging and degeneration. Osteoarthritis Cartilage 18: 416-423.

Sakai D (2008) Future perspectives of cell-based therapy for intervertebral disc disease. Eur Spine J 17 Suppl 4: 452-458.

Salgado AJ, Oliveira JT, Pedro AJ, Reis RL (2006) Adult stem cells in bone and cartilage tissue engineering. Curr Stem Cell Res Ther 1: 345-364.

Sobajima S, Vadala G, Shimer A, Kim JS, Gilbertson LG, Kang JD (2008) Feasibility of a stem cell therapy for intervertebral disc degeneration. Spine J 8: 888-896.

Strassburg S, Richardson SM, Freemont AJ, Hoyland JA (2010) Co-culture induces mesenchymal stem cell differentiation and modulation of the degenerate human nucleus pulposus cell phenotype. Regen Med 5: 701-711.

Vadalà G, Sobajima S, Lee JY, Huard J, Denaro V, Kang JD, Gilbertson LG (2008) In vitro interaction between muscle-derived stem cells and nucleus pulposus cells. Spine J 8: 804-809.

Watanabe T, Sakai D, Yamamoto Y, Iwashina T, Serigano K, Tamura F, Mochida J (2010) Human nucleus pulposus cells significantly enhanced biological properties in a coculture system with direct cell-to-cell contact with autologous mesenchymal stem cells. J Orthop Res 28: 623-630.

Weiler C, Nerlich AG, Schaaf R, Bachmeier BE, Wuertz $\mathrm{K}$, Boos N (2010) Immunohistochemical identification of notochordal markers in cells in the aging human lumbar intervertebral disc. Eur Spine J 19: 1761-1770.

Wykoff CC, Beasley NJ, Watson PH, Turner KJ, Pastorek J, Sibtain A, Wilson GD, Turley H, Talks KL, 
Maxwell PH, Pugh CW, Ratcliffe PJ, Harris AL (2000) Hypoxia-inducible expression of tumor-associated carbonic anhydrases. Cancer Res 60: 7075-7083.

Yang X, Li X (2009) Nucleus pulposus tissue engineering: a brief review. Eur Spine J 18: 1-9.

Yang SH, Wu CC, Shih TT, Sun YH, Lin FH (2008) In vitro study on interaction between human nucleus pulposus cells and mesenchymal stem cells through paracrine stimulation. Spine 33: 1951-1957.

Yang F, Leung VY, Luk KD, Chan D, Cheung KM (2009) Mesenchymal stem cells arrest intervertebral disc degeneration through chondrocytic differentiation and stimulation of endogenous cells. Mol Ther 17: 1959-1966.

\section{Discussion with Reviewer}

Reviewer I: Could the authors explain why they used a 2 $\%$ oxygen tension?

Authors: The intervertebral disc is an almost avascular tissue. As a result the oxygen tension within the disc is very low, and it has been well recognised that the cells in the NP evidence a robust hypoxic signal. Oxygen concentrations as low as $1 \%$ have been measured in the NP of the intervertebral disc (Ejeskär et al., 1979; Holm et al., 1981; Bartels et al., 1998; Lee et al., 2007, additional references). It has therefore been hypothesised that low oxygen tension promotes the differentiation of MSCs towards NP-like cells. In fact, differentiation towards the NP-like phenotype has been shown in MSCs cultured at $2 \%$ oxygen tension (Risbud et al., 2004, text reference). Similarly, given that cartilaginous tissues are also avascular, several studies have shown enhanced chondrogenesis of MSCs under hypoxic compared to normoxic conditions. While oxygen concentrations between $1 \%$ and $5 \%$ have generally been applied to create a hypoxic environment, $2-3 \%$ oxygen has been shown to promote chondrogenesis in human mesenchymal stem cells (e.g., Felka et al., 2009; Baumgartner et al., 2010; Markway et al., 2010, text references). Based on these data from current literature we postulated that an oxygen concentration of $2 \%$ would be a feasible hypoxic condition to study NP-like differentiation of MSCs.

Reviewer I: As an internal control, it could have been appropriate to use primary articular chondrocytes and cells derived from NP. Please comment!

Authors: Although the ultimate aim of MSC differentiation studies may be to reach a phenotype that is similar to the one of native chondrocytes or NP cells, we are aware that this cannot be achieved within a short culture time of a few weeks. While the expression of chondrogenic marker genes may approximate the levels of native disc or cartilage cells, the levels of MSC-derived cells are still orders of magnitude lower (Minogue et al., text reference; own unpublished observations). Hence we are investigating gene expression changes in response to a particular experimental condition or treatment rather than absolute gene expression values. With respect to the potential NP marker genes a comparison of the "best conditioned" MSCs, as evaluated in this study, with normal human NP cells may be appropriate. This will be the subject of a further study.

Reviewer I: Can insulin at this concentration really be considered an inducer of chondrogenesis?

Authors: Chondrogenic induction may start at higher insulin concentrations, when it competes with the IGFreceptor. While we agree that the "control" group may have experienced a minor chondrogenic stimulus, the survival of the MSCs had been found to be markedly reduced in a $3 \mathrm{D}$ environment and non-supplemented medium conditions. Therefore, we preferred to add ITS+ in order to maintain cell viability at an acceptable level in all groups. Furthermore, the minor up-regulation of aggrecan expression and the down-regulation of collagen type II expression in the normoxic control group at day 14 and 28 confirm that the chondrogenic effect of the control medium is insignificant for our study.

Reviewer I: As mentioned in the Introduction section "the ratio of GAG to Hydroxyproline could be used to distinguish IVD from cartilage tissue..." (Mwale et al., 2004). In this context, it is not clear why the authors did not measure this ratio?

Authors: From our results it is evident that the GAG amount that accumulated within the beads is considerably low in most of the groups, except in the TGF/Dex and GDF/ Dex groups. Given that the GAG content is generally higher than the hydroxyproline content, accurate quantification of the collagen amount was not possible, as most values were below the limit of quantification of the assay. Furthermore, the hydroxyproline assay would detect also the undesired collagen type I (i.e., detection of total collagen). We thus preferred to specifically assess the expression of collagen type II, which is more relevant for NP-like differentiation than the expression of collagen in general. Therefore the aggrecan:collagen II gene expression ratio is shown as well as qualitative immunostaining/blotting results; the latter demonstrate important trends, largely confirming gene expression data, although not quantitatively.

\section{Additional References}

Bartels EM, Fairbank JC, Winlove CP, Urban JP (1998) Oxygen and lactate concentrations measured in vivo in the intervertebral discs of patients with scoliosis and back pain. Spine 23: 1-7.

Ejeskär A, Holm S (1979) Oxygen tension measurements in the intervertebral disc. A methodological and experimental study. Ups J Med Sci 84: 83-93.

Holm S, Maroudas A, Urban JP, Selstam G, Nachemson A (1981) Nutrition of the intervertebral disc: solute transport and metabolism. Connect Tissue Res 8: 101-119.

Lee DC, Adams CS, Albert TJ, Shapiro IM, Evans SM, Koch CJ (2007) In situ oxygen utilization in the rat intervertebral disc. J Anat 210: 294-303. 